\title{
Environmental and Health-Related Risk Factors for Mycobacterium ulcerans Disease (Buruli Ulcer) in Benin
}

\author{
Fabienne Nackers, Roch C. Johnson, Judith R. Glynn, Claude Zinsou, René Tonglet, † and Françoise Portaels* \\ Epidemiology Unit, Université catholique de Louvain, Brussels, Belgium; Programme National de Lutte Contre l'Ulcère de Buruli, \\ Cotonou, Benin; Infectious Disease Epidemiology Unit, London School of Hygiene and Tropical Medicine, London, United \\ Kingdom; Centre Sanitaire et Nutritionnel Gbemonten, Zagnanado, Benin; Mycobacteriology Unit, Department of Microbiology, \\ Institute of Tropical Medicine, Antwerpen, Belgium
}

Abstract. We conducted a case-control study to investigate the association between Buruli ulcer (BU) and environmental- and health-related behaviors in southern Benin. Hospital BU cases $(N=324)$ and sex- and age-matched neighborhood controls $(N=1,173)$ answered a questionnaire. Regular use of soap for washing, treating injuries with soap or antibiotic powder, and frequent contact with flowing water appeared protective against BU.

\section{INTRODUCTION}

Buruli ulcer (BU) is a tropical skin disease caused by $M y$ cobacterium ulcerans. For decades, the disease had been linked to swampy environments, but BU risk factors remain poorly understood. Case-control studies conducted so far have suggested the use of unprotected water, ${ }^{1}$ wading in riv$\mathrm{ers}^{2}$ and farming close to rivers ${ }^{3}$ as potential risk factors for $\mathrm{BU}$, whereas wearing clothes during farming activities ${ }^{2,3}$ and using soap for washing ${ }^{2}$ were potential protective factors. Identification of modifiable risk factors that could lead to interventions for BU control in endemic areas is of primary importance. We report the results of a case-control study investigating the association between $\mathrm{BU}$ and some environmental and health-related behaviors in southern Benin. We used neighborhood controls to take account of the large geographic variation in environmental exposure to M. ulcerans.

\section{MATERIALS AND METHODS}

This study was part of a larger case-control study conducted from August 2002 to August 2003 in southern Benin to estimate the protective effectiveness of Bacillus Calmette Guerin (BCG) against BU. The methods of this study have been described elsewhere. ${ }^{4}$ Briefly, a series of clinically diagnosed BU cases were recruited in two health centers (the Center Sanitaire et Nutritionnel Gbemoten at Zagnanado and the Center de Dépistage et de Traitement de l'Ulcère de Buruli at Lalo). They were individually sex- and age-matched to neighborhood controls selected using a door-to-door systematic procedure starting from the case's house, aiming for four controls per case. Participants (or guardians for children) answered a questionnaire including questions on socioeconomic characteristics and environmental- and health-related factors. The questionnaire was pre-tested and translated into Fon and Adja, the local languages.

Odds ratios (ORs) and 95\% confidence intervals (95\% CIs) were calculated using conditional logistic regression. A multivariate model, adjusted for socioeconomic status, was built using a backward procedure. Data were analyzed with STATA (version 9.0). The study was approved by the Beninese Ministry of Public health.

* Address correspondence to Françoise Portaels, Nationalestraat 155, 2000 Antwerpen, Belgium. E-mail: portaels@itg.be

$\dagger$ Deceased.

\section{RESULTS}

In total, 1,173 controls were matched to 324 cases. Among cases, the median age was 13 years (11 months to 80 years), and $45 \%$ were female. One half of the cases were confirmed by at least one laboratory test positive for M. ulcerans, ${ }^{5}$ and $43 \%$ presented an ulcerative BU lesion. Because of matching, sex, age, and region of residence were similar in cases and controls. Cases were more likely than controls to live in cemented or brick houses and were of higher socioeconomic status as measured by a score of item ownership and education level of the head of the household. However, there was no evidence that education level of cases and controls differed. ${ }^{4}$ Associations of BU with environmental- and healthrelated risk factors are presented in Table 1. Risk of BU decreased with increasing frequency of contact with flowing water and increased with contact with stagnant water. Access to drinkable water was similar for cases and controls, but cases were more likely to fetch water from ponds, swamps, lakes, or backwaters and less often from rivers or streams. There was no evidence for an association between the risk of BU and farming on a daily basis or on marshy land. Farming without clothes covering the upper limbs was associated with a reduced risk of BU. Health-seeking behavior, as estimated by the use of traditional medicine and place to buy treatment during the last episode of illness, did not differ among cases and controls. Compared with cases, controls were more likely to have used soap, antibiotic powder, or gone to the health center for treating injuries and less often used mosquito nets. Using soap for washing on a daily basis was associated with a decreased risk of BU. A family history of BU was as frequent in controls as in cases.

In a multivariate analysis (Table 2), using soap or antibiotic powder to treat injuries, contact with flowing water, and using soap for washing were found to be independently associated with a decreased risk of BU. Farming without clothes covering upper limbs was not included in the multivariate model because the likely explanation was that those with lesions tended to cover them.

\section{DISCUSSION}

Our study suggests that simple hygiene measures could be important in preventing BU. Use of soap for washing was found to decrease the risk of BU as in a Ghanaian study, ${ }^{2}$ and treating injuries with soap or antibiotic powder also seemed 
TABLE 1

Associations of BU with environmental- and health-related variables - univariate analysis

\begin{tabular}{|c|c|c|c|c|c|}
\hline & Total cases/total controls & Cases $[N(\%)]$ & Controls $[N(\%)]$ & OR $[95 \% \mathrm{CI}]$ & $P$ value \\
\hline Contact with flowing water & $318 / 1,133$ & & & & $<0.001$ \\
\hline Never & & $175(55.0)$ & $414(36.5)$ & 1 & \\
\hline$<1$ time/day & & $101(31.8)$ & $375(33.1)$ & $0.46[0.32-0.66]$ & \\
\hline 1 time/day & & $42(13.2)$ & $344(30.4)$ & $0.10[0.06-0.18]$ & \\
\hline Contact with stagnant water & $315 / 1,133$ & & & & $0.002 \dagger$ \\
\hline Never & & $189(60.0)$ & $735(64.9)$ & 1 & \\
\hline$<1$ time/day & & $78(24.8)$ & $277(24.5)$ & $1.35[0.93-1.98]$ & \\
\hline 1 time/day & & $48(15.2)$ & $121(10.7)$ & $2.12[1.32-3.39]$ & \\
\hline Access to drinkable water $\ddagger$ & $324 / 1,173$ & $239(73.8)$ & $844(72.0)$ & $1.25[0.83-1.88]$ & 0.28 \\
\hline Fetch surface water for drinking & $321 / 1,146$ & & & & $<0.001$ \\
\hline No & & $269(83.8)$ & $953(81.6)$ & 1 & \\
\hline Yes, from river, stream & & $22(6.9)$ & $152(13.3)$ & $0.27[0.11-0.49]$ & \\
\hline Yes, from lake, pond, swamp, backwater & & $30(9.4)$ & $59(5.2)$ & $1.97[1.06-3.67]$ & \\
\hline Participation in farming & $320 / 1,149$ & & & & 0.45 \\
\hline$<1$ time/day & & $239(74.7)$ & $873(76.0)$ & 1 & \\
\hline 1 time/day & & $81(25.3)$ & $276(24.0)$ & $1.14[0.82-1.58]$ & \\
\hline Farming on marshy land/close to a water point & $318 / 1,134$ & & & & 0.26 \\
\hline Never & & $174(54.7)$ & $567(50.0)$ & 1 & \\
\hline$<1$ time/day & & $97(30.5)$ & $396(34.9)$ & $0.76[0.54-1.06]$ & \\
\hline 1 time/day & & $47(14.8)$ & $171(15.1)$ & $0.88[0.56-1.39]$ & \\
\hline Farming without clothes covering upper limbs & $318 / 1,139$ & & & & $<0.001$ \\
\hline Never & & $160(50.3)$ & $230(20.2)$ & 1 & \\
\hline$<1$ time/day & & $143(45.0)$ & $767(67.3)$ & $0.18[0.13-0.25]$ & \\
\hline 1 time/day & & $15(4.7)$ & $142(12.5)$ & $0.11[0.06-0.20]$ & \\
\hline Used traditional medicine during last episode of illness§ & $289 / 1,023$ & $17(5.9)$ & $47(4.6)$ & $1.48[0.79-2.78]$ & 0.23 \\
\hline Brought treatment $§$ & $290 / 1,024$ & & & & 0.50 \\
\hline No & & $19(6.6)$ & $65(6.4)$ & $0.95[0.51-1.76]$ & \\
\hline Health centre & & $183(63.1)$ & $613(59.9)$ & 1 & \\
\hline Market/traditional practitioner & & $88(30.3)$ & $346(33.8)$ & $0.82[0.59-1.15]$ & \\
\hline Treatment for injuries & $314 / 1,108$ & & & & $<0.001$ \\
\hline Nothing, water, plants & & $48(15.3)$ & $96(8.7)$ & 1 & \\
\hline Health centre, antibiotic powder, soap & & $266(84.7)$ & $1,012(9.3)$ & $0.46[0.30-0.69]$ & \\
\hline Uses soap for washing ( 1 time/day) & $320 / 1,149$ & $186(58.1)$ & $1,001(91.3)$ & $0.17[0.12-0.23]$ & $<0.001$ \\
\hline Uses mosquito nets & $320 / 1,120$ & $210(65.6)$ & $685(61.2)$ & $1.42[1.03-1.96]$ & 0.030 \\
\hline BU in the family $I$ & 296/998 & $38(12.8)$ & $127(12.7)$ & $1.05[0.70-1.60]$ & 0.80 \\
\hline
\end{tabular}

* likelihood ratio test-conditional logistic regression.

† Likelihood ratio test for trend.

Drinkable water: tap water, protected well, protected source, pump, water in bottle.

$\S$ Subjects reporting that they never had an injury/they had never been ill are considered as missing values.

II Grandparents/parents, brothers/sisters, children/grandchildren, wife/husband.

protective. If soap or antibiotic powder could prevent infection by $M$. ulcerans by cleaning the skin $^{2}$ or injuries, this could be of public health relevance. The decreased risk of BU with increased flowing water contacts could also be linked with cleanliness. This contrasts with previous studies reporting wading $^{2}$ and swimming ${ }^{6}$ in rivers as potential BU risk factors.
In the univariate analysis, cases reported more frequent contacts with stagnant water. The risks from water contact will depend on the environmental distribution of M. ulcerans in different settings.

Consistent with others studies, drawing water ${ }^{2,7}$ and farming activities ${ }^{2}$ were not found to be independently associated

TABLE 2

Associations of BU with environmental- and health-related variables-multivariate analysis

\begin{tabular}{|c|c|c|c|c|}
\hline & Cases $(N=291)$ & Controls $(N=970)$ & OR $[95 \% \mathrm{CI}]^{*}$ & $P \dagger$ \\
\hline Contact with flowing water & & & & $<0.001$ \\
\hline Never & $158(54.3)$ & $354(36.5)$ & 1 & \\
\hline$<1$ time $/ \mathrm{d}$ & $97(33.3)$ & $322(33.2)$ & $0.47[0.30-0.74]$ & \\
\hline 1 time $/ \mathrm{d}$ & $36(12.4)$ & $294(30.3)$ & $0.13[0.07-0.24]$ & \\
\hline Treatment for injuries & & & & $<0.001$ \\
\hline Nothing, water, plants & $45(15.5)$ & $87(9.0)$ & 1 & \\
\hline Health centre, antibiotic powder, soap & $246(84.6)$ & $883(91.0)$ & $0.41[0.25-0.67]$ & \\
\hline Uses soap for waiting (1 time/d) & $169(58.1)$ & $844(87.0)$ & $0.25[0.17-0.37]$ & $<0.001$ \\
\hline
\end{tabular}

* Adjusted for socioeconomic status (score of ownership and type of house).

$\dagger$ Likelihood ratio test-conditional logistic regression. 
with BU, nor was the use of mosquito nets. In contrast to previous reports, access to drinkable water ${ }^{1}$ did not seem to be associated with BU, and our data do not suggest that wearing clothes during farming activities is protective against BU. This could fit with the hypothesis of a possible immune protection against BU provided by frequent insect bites, ${ }^{8}$ but the most likely explanation is that subjects with BU typically wear clothes to hide skin lesions.

Our data were collected through a questionnaire. This cannot measure accurately the true variation in environmental contacts and health-related behaviors, and there is a possibility of recall and social desirability biases. Cases were interviewed in the hospital and were asked to recall the time before the lesion, which will have contributed to inaccuracies, and because cases and controls were interviewed in different places, different teams were used, and blinding was not possible. Nevertheless, the results fit with those from another study and the benefits of soap use go beyond BU. Soap is an uncontroversial, cheap, and potentially important intervention to prevent a severe emerging disease.

Received May 21, 2007. Accepted for publication August 4, 2007.

Acknowledgments: We thank Soeur Julia Aguiar for help and hospitality.

Financial support: This study was financed by the Damien Foundation (Brussels, Belgium). This study was also partly supported by the European Commission, project INCO-CT-2005-051476-BURULICO "Buruli ulcer: multidisciplinary research for improvement of control in Africa."

Authors' addresses: Fabienne Nackers, Université catholique de Louvain, Ecole de Santé Publique, Clos Chapelle-aux-champs 30/ EPID3058, 1200 Woluwé-Saint-Lambert, Belgium, Telephone: 32-27643320, Fax: 32-2-7643328, E-mail: Fabienne.Nackers@epid .ucl.ac.be. Roch C. Johnson, Programme National de Lutte contre l'Ulcère de Buruli au Bénin, Ministère de la Santé publique, 06 BP 2572, Cotonou, Benin, Telephone: 229-331827, Fax: 229-337057, Email: rochjohnson@yahoo.fr. Judith R. Glynn, London School of Hygiene and Tropical Medicine, Infectious Disease Epidemiology Unit,
Keppel Street, London WC1E 7HT, UK, Telephone: 44-20-79272423, Fax: 44-20-76368739, E-mail: Judith.Glynn@1shtm.ac.uk. Claude Zinsou, Centre Sanitaire et Nutritionnel de Gbemonten, Zagnanado, Benin, Fax: 229-520293. Françoise Portaels, Mycobacteriology Unit, Department of Microbiology, Institute of Tropical Medicine, Nationalestraat 155, 2000 Antwerpen, Belgium, Telephone: 32-3-2476317, Fax: 32-3-2476333, E-mail: portaels@itg.be.

\section{REFERENCES}

1. Debacker M, Portaels F, Aguiar J, Steunou C, Zinsou C, Meyers W, Dramaix M, 2006. Risk factors for Buruli ulcer, Benin. Emerg Infect Dis 12: 1325-1331.

2. Raghunathan PL, Whitney EA, Asamoa K, Stienstra Y, Taylor TH Jr, Amofah GK, Ofori-Adjei D, Dobos K, Guarner J, Martin S, Pathak S, Klutse E, Etuaful S, van der Graaf WT, van der Werf TS, King CH, Tappero JW, Ashford DA, 2005. Risk factors for Buruli ulcer disease (Mycobacterium ulcerans Infection): results from a case-control study in Ghana. Clin Infect Dis 40: 1445-1453.

3. Marston BJ, Diallo MO, Horsburgh CR Jr, Diomande I, Saki MZ, Kanga JM, Patrice G, Lipman HB, Ostroff SM, Good RC, 1995. Emergence of Buruli ulcer disease in the Daloa region of Côte d'Ivoire. Am J Trop Med Hyg 52: 219-224.

4. Nackers F, Dramaix M, Johnson RC, Zinsou C, Robert A, Biurrun DE, Bakedano E, Glynn JR, Portaels F, Tonglet R, 2006. BCG vaccine effectiveness against Buruli ulcer: a case-control study in Benin. Am J Trop Med Hyg 75: 768-774.

5. World Health Organization, 2001. Buruli ulcer. Diagnosis of Mycobacterium ulcerans disease. Portaels F, Johnson P, Meyers WM, eds. A Manual for Health Care Providers. Geneva: World Health Organization.

6. Aiga H, Amano T, Cairncross S, Adomako J, Nanas OK, Coleman S, 2004. Assessing water-related risk factors for Buruli ulcer: a case-control study in Ghana. Am J Trop Med Hyg 71: 387-392.

7. Barker DJ, Ninkibigaya V, 1972. Buruli disease and patients' activities. East Afr Med J 49: 260-268.

8. Marsollier L, Deniaux E, Brodin P, Marot A, Wondje CM, SaintAndre JP, Chauty A, Johnson C, Tekaia F, Yeramian E, Legras P, Carbonnelle B, Reysset G, Eyangoh S, Milon G, Cole ST, Aubry J, 2007. Protection against Mycobacterium ulcerans lesion development by exposure to aquatic insect saliva. PLoS Med 4: e64. 